\title{
Coupled implicit Caputo fractional q-difference systems
}

\author{
Saïd Abbas ${ }^{1}$, Mouffak Benchohra ${ }^{2,3}$, Bessem Samet ${ }^{3}$ and Yong Zhou Zh $^{4 *}$ (i)
}

"Correspondence:

yzhou@xtu.edu.cn

${ }^{4}$ Faculty of Information Technology,

Macau University of Science and

Technology, Macau, China

${ }^{5}$ Faculty of Mathematics and

Computational Science, Xiangtan

University, Hunan, China

Full list of author information is

available at the end of the article

\begin{abstract}
This paper deals with some existence, uniqueness, and Ulam stability results for a coupled implicit Caputo fractional q-difference system in Banach and generalized Banach spaces. Some applications are made of some fixed point theorems for the existence and uniqueness of solutions. Next we prove that our problem is generalized Ulam-Hyers-Rassias stable. Some illustrative examples are given in the last section.
\end{abstract}

MSC: $26 \mathrm{~A} 33$

Keywords: Fractional q-difference equation; Coupled system; Implicit; Ulam-Hyers-Rassias stability; Generalized Banach space

\section{Introduction}

Fractional differential equations have recently been applied in various areas of engineering, mathematics, physics, and other applied sciences [44]. For some fundamental results in the theory of fractional calculus and fractional differential equations, we refer the reader to the monographs [4-6, 33, 42, 47], the paper [46], and the references therein. Recently, considerable attention has been given to the existence of solutions of initial and boundary value problems for fractional differential equations with Caputo fractional derivative [5]. Implicit fractional differential equations were analyzed by many authors (see, for instance, $[4,5,22,23,34,43]$ and the references therein). Considerable attention has been given to the study of the Ulam stability of functional differential and integral equations; one can see the monograph [6], the papers [3, 17-20, 28, 29, 31, 32, 39-41], and the references therein.

Fractional q-difference equations initiated at the beginning of the nineteenth century $[10,24]$ and received significant attention in recent years [21, 26]. Some interesting details about initial and boundary value problems of q-difference and fractional q-difference equations can be found in $[7-9,12-16,25,27,35]$ and the references therein.

In [1, 2], Abbas et al. considered some existence results for some coupled fractional differential systems in generalized Banach spaces.

(c) The Author(s) 2019. This article is licensed under a Creative Commons Attribution 4.0 International License, which permits use, sharing, adaptation, distribution and reproduction in any medium or format, as long as you give appropriate credit to the original author(s) and the source, provide a link to the Creative Commons licence, and indicate if changes were made.The images or other third party material in this article are included in the article's Creative Commons licence, unless indicated otherwise in a credit line to the material. If material is not included in the article's Creative Commons licence and your intended use is not permitted by statutory regulation or exceeds the permitted use, you will need to obtain permission directly from the copyright holder.To view a copy of this licence, visit http://creativecommons.org/licenses/by/4.0/. 
In this paper we discuss the existence and Ulam-Hyers-Rassias stability of solutions for the following coupled implicit fractional q-difference system:

$$
\left\{\begin{array}{l}
\left({ }^{c} D_{q}^{\alpha_{1}} u_{1}\right)(t)=f_{1}\left(t, u_{1}(t), u_{2}(t),\left({ }^{c} D_{q}^{\alpha_{1}} u_{1}\right)(t)\right), \\
\left({ }^{c} D_{q}^{\alpha_{2}} u_{2}\right)(t)=f_{2}\left(t, u_{1}(t), u_{2}(t),\left({ }^{c} D_{q}^{\alpha_{2}} u_{2}\right)(t)\right),
\end{array} \quad t \in I:=[0, T],\right.
$$

with the initial conditions

$$
\left(u_{1}(0), u_{2}(0)\right)=\left(u_{01}, u_{02}\right)
$$

where $q \in(0,1), T>0, \alpha_{i} \in(0,1], f_{i}: I \times \mathbb{R} \times \mathbb{R} \times \mathbb{R} \rightarrow \mathbb{R}, i=1,2$, are given continuous functions, and ${ }^{c} D_{q}^{\alpha_{i}}$ is the Caputo fractional q-difference derivative of order $\alpha_{i}, i=1,2$.

Next, we discuss the existence and uniqueness of solutions for problem (1)-(2) in generalized Banach spaces, where $f_{i}: I \times \mathbb{R}^{3 m} \rightarrow \mathbb{R}^{m}, i=1,2$, are given continuous functions, $\mathbb{R}^{m}, m \in \mathbb{N}^{*}$, is the Euclidian Banach space with a suitable norm $\|\cdot\|$. This paper initiates the study of implicit coupled Caputo fractional q-difference systems in Banach and generalized Banach spaces.

\section{Preliminaries}

Consider the Banach space $C(I):=C(I, \mathbb{R})$ of continuous functions from $I$ into $\mathbb{R}$ equipped with the usual supremum (uniform) norm

$$
\|u\|_{\infty}:=\sup _{t \in I}|u(t)|
$$

As usual, $L^{1}(I)$ denotes the space of measurable functions $v: I \rightarrow \mathbb{R}$ which are Lebesgue integrable with the norm

$$
\|v\|_{1}=\int_{0}^{T}|v(t)| d t
$$

Let us recall some definitions and properties of fractional q-calculus. For $a \in \mathbb{R}$, we set

$$
[a]_{q}=\frac{1-q^{a}}{1-q} .
$$

The q-analogue of the power $(a-b)^{n}$ is

$$
(a-b)^{(0)}=1, \quad(a-b)^{(n)}=\prod_{k=0}^{n-1}\left(a-b q^{k}\right), \quad a, b \in \mathbb{R}, n \in \mathbb{N} .
$$

In general,

$$
(a-b)^{(\alpha)}=a^{\alpha} \prod_{k=0}^{\infty}\left(\frac{a-b q^{k}}{a-b q^{k+\alpha}}\right), \quad a, b, \alpha \in \mathbb{R} .
$$

Definition 2.1 ([30]) The q-gamma function is defined by

$$
\Gamma_{q}(\xi)=\frac{(1-q)^{(\xi-1)}}{(1-q)^{\xi-1}}, \quad \xi \in \mathbb{R}-\{0,-1,-2, \ldots\} .
$$


Notice that the q-gamma function satisfies $\Gamma_{q}(1+\xi)=[\xi]_{q} \Gamma_{q}(\xi)$.

Definition 2.2 ([30]) The q-derivative of order $n \in \mathbb{N}$ of a function $u: I \rightarrow \mathbb{R}$ is defined by $\left(D_{q}^{0} u\right)(t)=u(t)$,

$$
\left(D_{q} u\right)(t):=\left(D_{q}^{1} u\right)(t)=\frac{u(t)-u(q t)}{(1-q) t}, \quad t \neq 0, \quad\left(D_{q} u\right)(0)=\lim _{t \rightarrow 0}\left(D_{q} u\right)(t),
$$

and

$$
\left(D_{q}^{n} u\right)(t)=\left(D_{q} D_{q}^{n-1} u\right)(t), \quad t \in I, n \in\{1,2, \ldots\} .
$$

Set $I_{t}:=\left\{t q^{n}: n \in \mathbb{N}\right\} \cup\{0\}$.

Definition 2.3 ([30]) The q-integral of a function $u: I_{t} \rightarrow \mathbb{R}$ is defined by

$$
\left(I_{q} u\right)(t)=\int_{0}^{t} u(s) d_{q} s=\sum_{n=0}^{\infty} t(1-q) q^{n} f\left(t q^{n}\right)
$$

provided that the series converges.

We note that $\left(D_{q} I_{q} u\right)(t)=u(t)$, while if $u$ is continuous at 0 , then

$$
\left(I_{q} D_{q} u\right)(t)=u(t)-u(0)
$$

Definition 2.4 ([11]) The Riemann-Liouville fractional q-integral of order $\alpha \in \mathbb{R}_{+}:=$ $[0, \infty)$ of a function $u: I \rightarrow \mathbb{R}$ is defined by $\left(I_{q}^{0} u\right)(t)=u(t)$, and

$$
\left(I_{q}^{\alpha} u\right)(t)=\int_{0}^{t} \frac{(t-q s)^{(\alpha-1)}}{\Gamma_{q}(\alpha)} u(s) d_{q} s, \quad t \in I .
$$

Lemma 2.5 ([37]) For $\alpha \in \mathbb{R}_{+}:=[0, \infty)$ and $\lambda \in(-1, \infty)$, we have

$$
\left(I_{q}^{\alpha}(t-a)^{(\lambda)}\right)(t)=\frac{\Gamma_{q}(1+\lambda)}{\Gamma(1+\lambda+\alpha)}(t-a)^{(\lambda+\alpha)}, \quad 0<a<t<T .
$$

In particular,

$$
\left(I_{q}^{\alpha} 1\right)(t)=\frac{1}{\Gamma_{q}(1+\alpha)} t^{(\alpha)}
$$

Definition 2.6 ([38]) The Riemann-Liouville fractional q-derivative of order $\alpha \in \mathbb{R}_{+}$of a function $u: I \rightarrow \mathbb{R}$ is defined by $\left(D_{q}^{0} u\right)(t)=u(t)$, and

$$
\left(D_{q}^{\alpha} u\right)(t)=\left(D_{q}^{[\alpha]} I_{q}^{[\alpha]-\alpha} u\right)(t), \quad t \in I
$$

where $[\alpha]$ is the integer part of $\alpha$. 
Definition 2.7 ([38]) The Caputo fractional q-derivative of order $\alpha \in \mathbb{R}_{+}$of a function $u: I \rightarrow \mathbb{R}$ is defined by $\left({ }^{C} D_{q}^{0} u\right)(t)=u(t)$, and

$$
\left({ }^{C} D_{q}^{\alpha} u\right)(t)=\left(I_{q}^{[\alpha]-\alpha} D_{q}^{[\alpha]} u\right)(t), \quad t \in I
$$

Lemma 2.8 ([38]) Let $\alpha \in \mathbb{R}_{+}$. Then the following equality holds:

$$
\left(I_{q}^{\alpha C} D_{q}^{\alpha} u\right)(t)=u(t)-\sum_{k=0}^{[\alpha]-1} \frac{t^{k}}{\Gamma_{q}(1+k)}\left(D_{q}^{k} u\right)(0) .
$$

In particular, if $\alpha \in(0,1)$, then

$$
\left(I_{q}^{\alpha C} D_{q}^{\alpha} u\right)(t)=u(t)-u(0)
$$

From the above lemma, and in order to define the solution for problem (1)-(2), we conclude the following lemma.

Lemma 2.9 Let $f: I \times \mathbb{R}^{3 m} \rightarrow \mathbb{R}^{m}$ such that $f_{i}\left(\cdot, u_{i}, v_{i}, w_{i}\right) \in C(I)$ for each $u_{i}, v_{i}, w_{i} \in \mathbb{R}^{m}$. Then problem (1)-(2) is equivalent to the problem of obtaining the solutions of the integral equation

$$
g_{i}(t)=f_{i}\left(t, u_{01}+\left(I_{q}^{\alpha_{1}} g_{1}\right)(t), u_{02}+\left(I_{q}^{\alpha_{2}} g_{2}\right)(t), g_{i}(t)\right), \quad i=1,2
$$

and if $g_{i}(\cdot) \in C(I)$ is the solution of this equation, then

$$
u_{i}(t)=u_{0 i}+\left(I_{q}^{\alpha_{i}} g_{i}\right)(t)
$$

\section{Existence and Ulam stability results}

In this section, we are concerned with the existence stability of solutions of system (1)-(2). We denote by $\mathcal{C}:=C(I) \times C(I)$ the Banach space with the norm

$$
\|(u, v)\|_{\mathcal{C}}=\|u\|_{\infty}+\|v\|_{\infty}
$$

Definition 3.1 By a solution of problem (1)-(2) we mean a coupled function $(u, v) \in \mathcal{C}$ that satisfies the system

$$
\left\{\begin{array}{l}
\left({ }^{c} D_{q}^{\alpha_{1}} u\right)(t)=f_{1}\left(t, u(t), v(t),\left({ }^{c} D_{q}^{\alpha_{1}} u\right)(t)\right) \\
\left({ }^{c} D_{q}^{\alpha_{2}} v\right)(t)=f_{2}\left(t, u(t), v(t),\left({ }^{c} D_{q}^{\alpha_{2}} v\right)(t)\right)
\end{array}\right.
$$

on $I$ and the initial condition $(u(0), v(0))=\left(u_{01}, u_{02}\right)$.

Now, we consider the Ulam stability for system (1)-(2). Let $\epsilon>0$ and $\Phi: I \rightarrow \mathbb{R}_{+}$be a continuous function. We consider the following inequalities:

$$
\left\{\begin{array}{l}
\left|\left({ }^{c} D_{q}^{\alpha_{1}} u\right)(t)-f_{1}\left(t, u(t), v(t),\left({ }^{c} D_{q}^{\alpha_{1}} u\right)(t)\right)\right| \leq \epsilon, \\
\left|\left({ }^{c} D_{q}^{\alpha_{2}} v\right)(t)-f_{2}\left(t, u(t), v(t),\left({ }^{c} D_{q}^{\alpha_{2}} v\right)(t)\right)\right| \leq \epsilon,
\end{array} \quad t \in I ;\right.
$$




$$
\begin{aligned}
& \left\{\begin{array}{l}
\left|\left({ }^{c} D_{q}^{\alpha_{1}} u\right)(t)-f_{1}\left(t, u(t), v(t),\left({ }^{c} D_{q}^{\alpha_{1}} u\right)(t)\right)\right| \leq \Phi(t) \\
\left|\left({ }^{c} D_{q}^{\alpha_{2}} v\right)(t)-f_{2}\left(t, u(t), v(t),\left({ }^{c} D_{q}^{\alpha_{2}} v\right)(t)\right)\right| \leq \Phi(t),
\end{array} \quad t \in I ;\right. \\
& \left\{\begin{array}{l}
\left|\left({ }^{c} D_{q}^{\alpha_{1}} u\right)(t)-f_{1}\left(t, u(t), v(t),\left({ }^{c} D_{q}^{\alpha_{1}} u\right)(t)\right)\right| \leq \epsilon \Phi(t) \\
\left|\left({ }^{c} D_{q}^{\alpha_{2}} v\right)(t)-f_{2}\left(t, u(t), v(t),\left({ }^{c} D_{q}^{\alpha_{2}} v\right)(t)\right)\right| \leq \epsilon \Phi(t),
\end{array} \quad t \in I .\right.
\end{aligned}
$$

Set

$$
|(u(t), v(t))|:=|u(t)|+|v(t)|
$$

Definition $3.2([5,40])$ System $(1)-(2)$ is Ulam-Hyers stable if there exists a real number $c_{f_{1}, f_{2}}>0$ such that, for each $\epsilon>0$ and for each solution $\left(u_{1}, v_{1}\right) \in \mathcal{C}$ of inequalities (3), there exists a solution $(u, v) \in C(I)$ of $(1)-(2)$ with

$$
\left|\left(u_{1}(t)-u(t), v_{1}(t)-v(t)\right)\right| \leq \epsilon c_{f_{1}, f_{2}}, \quad t \in I
$$

Definition 3.3 ([5, 40]) System (1)-(2) is generalized Ulam-Hyers stable if there exists $c_{f_{1}, f_{2}}: C\left(\mathbb{R}_{+}, \mathbb{R}_{+}\right)$with $c_{f_{i}}(0)=0, i=1,2$, such that, for each $\epsilon>0$ and for each solution $\left(u_{1}, v_{1}\right) \in \mathcal{C}$ of inequalities (3), there exists a solution $(u, v) \in \mathcal{C}$ of $(1)-(2)$ with

$$
\left|\left(u_{1}(t)-u(t), v_{1}(t)-v(t)\right)\right| \leq c_{f_{1}, f_{2}}(\epsilon), \quad t \in I .
$$

Definition 3.4 ([5, 40]) System (1)-(2) is Ulam-Hyers-Rassias stable with respect to $\Phi$ if there exists a real number $c_{f_{1}, f_{2}, \Phi}>0$ such that, for each $\epsilon>0$ and for each solution $\left(u_{1}, v_{1}\right) \in \mathcal{C}$ of inequalities (5), there exists a solution $(u, v) \in \mathcal{C}$ of $(1)-(2)$ with

$$
\left|\left(u_{1}(t)-u(t), v_{1}(t)-v(t)\right)\right| \leq \epsilon c_{f_{1}, f_{2}, \Phi} \Phi(t), \quad t \in I .
$$

Definition $3.5([5,40])$ System $(1)-(2)$ is generalized Ulam-Hyers-Rassias stable with respect to $\Phi$ if there exists a real number $c_{f_{1}, f_{2}, \Phi}>0$ such that, for each solution $\left(u_{1}, v_{1}\right) \in \mathcal{C}$ of inequalities (4), there exists a solution $(u, v) \in \mathcal{C}$ of $(1)-(2)$ with

$$
\left|\left(u_{1}(t)-u(t), v_{1}(t)-v(t)\right)\right| \leq c_{f_{1}, f_{2}, \Phi} \Phi(t), \quad t \in I .
$$

Remark 3.6 It is clear that

(i) Definition $3.2 \Rightarrow$ Definition 3.3,

(ii) Definition $3.4 \Rightarrow$ Definition 3.5 ,

(iii) Definition 3.4 for $\Phi(\cdot)=1 \Rightarrow$ Definition 3.2.

One can have similar remarks for inequalities (3) and (5).

Theorem 3.7 (Schauder's fixed point theorem) Let $X$ be a Banach space, $D$ be a bounded closed convex subset of $X$, and $T: D \rightarrow D$ be a compact and continuous map. Then $T$ has at least one fixed point in $D$.

The following hypotheses will be used in the sequel: 
$\left(H_{1}\right)$ There exist functions $p_{i}, d_{i}, r_{i} \in C(I,[0, \infty)), i=1,2$, with $r_{i}(t)<1$ such that

$$
\left|f_{i}(t, u, v, w)\right| \leq p_{i}(t)+d_{i}(t) \min (|u|,|v|)+r_{i}(t)|w|
$$

for each $t \in I$ and $u, v, w \in \mathbb{R}$;

$\left(H_{2}\right)$ There exists $\lambda_{\Phi}>0$ such that, for each $t \in I$, we have

$$
\left(I_{q}^{\alpha_{i}} \Phi\right)(t) \leq \lambda_{\Phi} \Phi(t), \quad i=1,2 .
$$

Set

$$
\begin{aligned}
& L_{i}:=\frac{T^{\alpha_{i}}}{\Gamma_{q}\left(1+\alpha_{i}\right)}, \\
& p_{i}^{*}=\sup _{t \in I} p_{i}(t), \quad d_{i}^{*}=\sup _{t \in I} d_{i}(t), \quad r_{i}^{*}=\sup _{t \in I} r_{i}(t), \quad \Phi^{*}=\sup _{t \in I} \Phi(t) .
\end{aligned}
$$

Theorem 3.8 Assume that hypothesis $\left(H_{1}\right)$ holds. If

$$
r_{1}^{*}+r_{2}^{*}-r_{1}^{*} r_{2}^{*}+\left(1-r_{2}^{*}\right) L_{1} d_{1}^{*}+\left(1-r_{1}^{*}\right) L_{2} d_{2}^{*}<1,
$$

then system (1)-(2) has at least one solution defined on I. Moreover, if hypothesis $\left(H_{2}\right)$ holds, then system (1)-(2) is generalized Ulam-Hyers-Rassias stable.

Proof Define the operators $N_{i}: C(I) \rightarrow C(I), i=1,2$, by

$$
\left(N_{1} u\right)(t)=u_{01}+\left(I_{q}^{\alpha_{1}} g_{1}\right)(t), \quad t \in I,
$$

and

$$
\left(N_{2} v\right)(t)=u_{02}+\left(I_{q}^{\alpha_{2}} g_{2}\right)(t), \quad t \in I,
$$

where $g_{i} \in C(I)$ such that

$$
g_{i}(t)=f\left(t, u(t), v(t), g_{i}(t)\right) .
$$

Consider the continuous operator $N: \mathcal{C} \rightarrow \mathcal{C}$ defined by

$$
(N(u, v))(t)=\left(\left(N_{1} u\right)(t),\left(N_{2} v\right)(t)\right) .
$$

Set

$$
R \geq \frac{\left(1-r_{1}^{*}\right)\left(1-r_{2}^{*}\right)\left(\left|u_{01}\right|+\left|u_{02}\right|\right)+\left(1-r_{2}^{*}\right) L_{1} p_{1}^{*}+\left(1-r_{1}^{*}\right) L_{2} p_{2}^{*}}{1-r_{1}^{*}-r_{2}^{*}+r_{1}^{*} r_{2}^{*}-\left(1-r_{2}^{*}\right) L_{1} d_{1}^{*}-\left(1-r_{1}^{*}\right) L_{2} d_{2}^{*}}
$$

and consider the closed and convex ball $B_{R}=\left\{u \in \mathcal{C}:\|(u, v)\|_{\mathcal{C}} \leq R\right\}$.

Let $u \in B_{R}$. Then, for each $t \in I$, we have

$$
\left|\left(N_{1} u\right)(t)\right| \leq\left|u_{01}\right|+\int_{0}^{t} \frac{(t-q s)^{\left(\alpha_{1}-1\right)}}{\Gamma_{q}\left(\alpha_{1}\right)}\left|g_{1}(s)\right| d_{q} s
$$


and

$$
\left|\left(N_{2} v\right)(t)\right| \leq\left|u_{02}\right|+\int_{0}^{t} \frac{(t-q s)^{\left(\alpha_{2}-1\right)}}{\Gamma_{q}\left(\alpha_{2}\right)}\left|g_{2}(s)\right| d_{q} s
$$

By using $\left(H_{1}\right)$, for each $t \in I$, we have

$$
\begin{aligned}
\left|g_{i}(t)\right| & \leq p_{i}(t)+d_{i}(t) \min (|u(t)|,|v(t)|)+r_{i}(t)\left|g_{i}(t)\right| \\
& \leq p_{i}^{*}+d_{i}^{*} R+r_{i}^{*}\left|g_{i}(t)\right| .
\end{aligned}
$$

Thus

$$
\left|g_{i}(t)\right| \leq \frac{p_{i}^{*}+d_{i}^{*} R}{1-r_{i}^{*}}
$$

Hence

$$
\left\|N_{1}(u)\right\|_{\infty} \leq\left|u_{01}\right|+\frac{L_{1}\left(p_{1}^{*}+d_{1}^{*} R\right)}{1-r_{1}^{*}}
$$

and

$$
\left\|N_{2}(v)\right\|_{\infty} \leq\left|u_{02}\right|+\frac{L_{2}\left(p_{2}^{*}+d_{2}^{*} R\right)}{1-r_{2}^{*}}
$$

This implies that

$$
\begin{aligned}
\|N(u, v)\|_{\mathcal{C}} & =\left\|N_{1}(u)\right\|_{\infty}+\left\|N_{2}(v)\right\|_{\infty} \\
& \leq\left|u_{01}\right|+\left|u_{02}\right|+\sum_{i=1}^{2} \frac{L_{i}\left(p_{i}^{*}+d_{i}^{*} R\right)}{1-r_{i}^{*}} \\
& \leq R .
\end{aligned}
$$

This proves that $N$ maps the ball $B_{R}$ into $B_{R}$. We shall show that the operator $N: B_{R} \rightarrow B_{R}$ is continuous and compact. The proof will be given in several steps.

Step 1: $N$ is continuous.

Let $\left\{u_{n}\right\}_{n \in \mathbb{N}}$ and $\left\{v_{n}\right\}_{n \in \mathbb{N}}$ be two sequences such that $\left(u_{n}, v_{n}\right) \rightarrow(u, v)$ in $B_{R}$. Then, for each $t \in I$, we have

$$
\left|\left(N_{1} u_{n}\right)(t)-\left(N_{1} u\right)(t)\right| \leq \int_{0}^{t} \frac{(t-q s)^{\left(\alpha_{1}-1\right)}}{\Gamma_{q}\left(\alpha_{1}\right)}\left|\left(g_{1 n}(s)-g_{1}(s)\right)\right| d_{q} s
$$

and

$$
\left|\left(N_{2} v_{n}\right)(t)-\left(N_{2} v\right)(t)\right| \leq \int_{0}^{t} \frac{(t-q s)^{\left(\alpha_{2}-1\right)}}{\Gamma_{q}\left(\alpha_{2}\right)}\left|\left(g_{2 n}(s)-g_{2}(s)\right)\right| d_{q} s
$$

where $g_{i n}, g_{i} \in C(I), i=1,2$, such that

$$
g_{\text {in }}(t)=f_{i}\left(t, u_{n}(t), v_{n}(t), g_{\text {in }}(t)\right)
$$


and

$$
g_{i}(t)=f_{i}\left(t, u(t), v(t), g_{i}(t)\right) \text {. }
$$

Since $\left(u_{n}, v_{n}\right) \rightarrow u$ as $n \rightarrow \infty$ and $f_{i}$ are continuous functions, we get

$$
g_{\text {in }}(t) \rightarrow g_{i}(t) \quad \text { as } n \rightarrow \infty \text { for each } t \in I
$$

Thus

$$
\left\|N_{1}\left(u_{n}\right)-N_{1}(u)\right\|_{\infty} \leq \frac{p_{1}^{*}+d_{1}^{*} R}{1-r_{1}^{*}}\left\|g_{1 n}-g_{1}\right\|_{\infty} \rightarrow 0 \quad \text { as } n \rightarrow \infty
$$

and

$$
\left\|N_{2}\left(v_{n}\right)-N_{2}(v)\right\|_{\infty} \leq \frac{p_{2}^{*}+d_{2}^{*} R}{1-r_{2}^{*}}\left\|g_{2 n}-g_{2}\right\|_{\infty} \rightarrow 0 \quad \text { as } n \rightarrow \infty .
$$

Hence

$$
\left\|N\left(u_{n}, v_{n}\right)-N(u, v)\right\|_{\mathcal{C}} \rightarrow 0 \quad \text { as } n \rightarrow \infty
$$

Step 2: $N\left(B_{R}\right)$ is bounded. This is clear since $N\left(B_{R}\right) \subset B_{R}$ and $B_{R}$ is bounded.

Step 3: $N$ maps bounded sets into equicontinuous sets in $B_{R}$.

Let $t_{1}, t_{2} \in I$ such that $t_{1}<t_{2}$, and let $(u, v) \in B_{R}$. Then we have

$$
\begin{aligned}
\left|\left(N_{i} u\right)\left(t_{1}\right)-\left(N_{i} u\right)\left(t_{2}\right)\right| \leq & \int_{0}^{t_{1}} \frac{\left|\left(t_{2}-q s\right)^{\left(\alpha_{i}-1\right)}-\left(t_{1}-q s\right)^{\left(\alpha_{i}-1\right)}\right|}{\Gamma_{q}\left(\alpha_{i}\right)}\left|g_{i}(s)\right| d_{q} s \\
& +\int_{t_{1}}^{t_{2}} \frac{\left|\left(t_{2}-q s\right)^{\left(\alpha_{i}-1\right)}\right|}{\Gamma_{q}\left(\alpha_{i}\right)}\left|g_{i}(s)\right| d_{q} s,
\end{aligned}
$$

where $g_{i} \in C(I)$ such that $g_{i}(t)=f\left(t, u(t), v(t), g_{i}(t)\right)$. Hence

$$
\begin{aligned}
\left|\left(N_{1} u\right)\left(t_{1}\right)-\left(N_{1} u\right)\left(t_{2}\right)\right| \leq & \frac{p_{1}^{*}+d_{1}^{*} R}{1-r_{1}^{*}} \int_{0}^{t_{1}} \frac{\left|\left(t_{2}-q s\right)^{\left(\alpha_{1}-1\right)}-\left(t_{1}-q s\right)^{\left(\alpha_{1}-1\right)}\right|}{\Gamma_{q}\left(\alpha_{1}\right)} d_{q} s \\
& +\frac{p_{1}^{*}+d_{1}^{*} R}{1-r_{1} *} \int_{t_{1}}^{t_{2}} \frac{\left|\left(t_{2}-q s\right)^{\left(\alpha_{1}-1\right)}\right|}{\Gamma_{q}\left(\alpha_{1}\right)} d_{q} s \\
\rightarrow & 0 \text { as } t_{1} \rightarrow t_{2},
\end{aligned}
$$

and

$$
\begin{aligned}
\left|\left(N_{2} v\right)\left(t_{1}\right)-\left(N_{2} v\right)\left(t_{2}\right)\right| \leq & \frac{p_{2}^{*}+d_{2}^{*} R}{1-r_{2}^{*}} \int_{0}^{t_{1}} \frac{\left|\left(t_{2}-q s\right)^{\left(\alpha_{2}-1\right)}-\left(t_{1}-q s\right)^{\left(\alpha_{2}-1\right)}\right|}{\Gamma_{q}\left(\alpha_{2}\right)} d_{q} s \\
& +\frac{p_{2}^{*}+d_{2}^{*} R}{1-r_{2} *} \int_{t_{1}}^{t_{2}} \frac{\left|\left(t_{2}-q s\right)^{\left(\alpha_{2}-1\right)}\right|}{\Gamma_{q}\left(\alpha_{2}\right)} d_{q} s \\
\rightarrow & 0 \text { as } t_{1} \rightarrow t_{2} .
\end{aligned}
$$


As a consequence of the above three steps with the Arzelá-Ascoli theorem, we can conclude that $N: B_{R} \rightarrow B_{R}$ is continuous and compact. From an application of Theorem 3.7, we deduce that $N$ has at least a fixed point $(u, v)$ which is a solution of our system (1)-(2).

Step 4: Generalized Ulam-Hyers-Rassias stability.

Let $\left(u_{1}, v_{1}\right)$ be a solution of inequality (4), and let us assume that $(u, v)$ is a solution of system (1)-(2). Thus, we have

$$
(u(t), v(t))=\left(u_{01}+\left(I_{q}^{\alpha_{1}} g_{1}\right)(t), u_{02}+\left(I_{q}^{\alpha_{2}} g_{2}\right)(t),\right.
$$

where $g_{i} \in C(I), i=1,2$, such that $g_{i}(t)=f\left(t, u(t), v(t), g_{i}(t)\right)$.

From inequality (4) for each $t \in I$, we have

$$
\left|u_{1}(t)-u_{01}-\left(I_{q}^{\alpha_{1}} g_{1}\right)(t)\right| \leq\left(I_{q}^{\alpha_{1}} \Phi\right)(t)
$$

and

$$
\left|v_{1}(t)-u_{02}-\left(I_{q}^{\alpha_{2}} g_{2}\right)(t)\right| \leq\left(I_{q}^{\alpha_{2}} \Phi\right)(t)
$$

From hypotheses $\left(H_{1}\right)$ and $\left(H_{2}\right)$, for each $t \in I$, we have

$$
\begin{aligned}
\left|u(t)-u_{1}(t)\right| & \leq\left|u(t)-u_{01}-\left(I_{q}^{\alpha_{1}} g_{1}\right)(t)+\left(I_{q}^{\alpha_{1}}\left(g_{1}-g_{2}\right)\right)(t)\right| \\
& \leq\left(I_{q}^{\alpha_{1}} \Phi\right)(t)+\int_{0}^{t} \frac{(t-q s)^{\left(\alpha_{1}-1\right)}}{\Gamma_{q}\left(\alpha_{1}\right)}\left(\left|g_{1}(s)\right|+\left|g_{2}(s)\right|\right) d_{q} s \\
& \leq\left(I_{q}^{\alpha_{1}} \Phi\right)(t)+\frac{p_{1}^{*}+d_{1}^{*}}{1-r_{1}^{*}}\left(I_{q}^{\alpha_{1}} \Phi\right)(t) \\
& \leq \lambda_{\phi} \Phi(t)+2 \lambda_{\phi} \frac{p_{1}^{*}+d_{1}^{*}}{1-r_{1}^{*}} \Phi(t) \\
& \leq\left[1+2 \frac{p_{1}^{*}+d_{1}^{*}}{1-r_{1}^{*}}\right] \lambda_{\phi} \Phi(t) \\
& :=c_{f_{1}, \Phi} \Phi(t) .
\end{aligned}
$$

Also, we get

$$
\begin{aligned}
\left|v(t)-v_{1}(t)\right| & \leq\left[1+2 \frac{p_{2}^{*}+d_{2}^{*}}{1-r_{2}^{*}}\right] \lambda_{\phi} \Phi(t) \\
& :=c_{f_{2}, \Phi} \Phi(t) .
\end{aligned}
$$

Thus

$$
\begin{aligned}
\left|(u(t), v(t))-\left(u_{1}(t), v_{1}(t)\right)\right| & =\left|u(t)-u_{1}(t)\right|+\left|v(t)-v_{1}(t)\right| \\
& \leq\left[\lambda_{\phi} \sum_{i=1}^{2}\left(1+2 \frac{p_{i}^{*}+d_{i}^{*}}{1-r_{i}^{*}}\right)\right] \Phi(t) \\
& :=c_{f_{1}, f_{2}, \Phi} \Phi(t) .
\end{aligned}
$$

Hence, problem (1)-(2) is generalized Ulam-Hyers-Rassias stable. 


\section{Results in generalized Banach spaces}

Now, we are concerned with the existence and uniqueness results of the coupled system (1)-(2) in generalized Banach spaces.

Let $C$ be the Banach space of all continuous functions $v$ from $I$ into $\mathbb{R}^{m}$ with the supremum (uniform) norm

$$
\|v\|_{C}:=\sup _{t \in I}\|v(t)\|
$$

By $L^{\infty}\left(I, \mathbb{R}_{+}\right)$we denote the Banach space of measurable functions from $I$ into $\mathbb{R}_{+}$which are essentially bounded.

$$
\begin{aligned}
& \text { Let } x, y \in \mathbb{R}^{m} \text { with } x=\left(x_{1}, x_{2}, \ldots, x_{m}\right), y=\left(y_{1}, y_{2}, \ldots, y_{m}\right) . \\
& \text { By } x \leq y \text { we mean } x_{i} \leq y_{i}, i=1, \ldots, m \text {. Also, } \\
& \quad|x|=\left(\left|x_{1}\right|,\left|x_{2}\right|, \ldots,\left|x_{m}\right|\right), \\
& \quad \max (x, y)=\left(\max \left(x_{1}, y_{1}\right), \max \left(x_{2}, y_{2}\right), \ldots, \max \left(x_{m}, y_{m}\right)\right),
\end{aligned}
$$

and

$$
\mathbb{R}_{+}^{m}=\left\{x \in \mathbb{R}^{m}: x_{i} \in \mathbb{R}_{+}, i=1, \ldots, m\right\}
$$

If $c \in \mathbb{R}$, then $x \leq c$ means $x_{i} \leq c, i=1, \ldots, m$.

Definition 4.1 Let $X$ be a nonempty set. By a vector-valued metric on $X$ we mean a map $d: X \times X \rightarrow \mathbb{R}^{m}$ with the following properties:

(i) $d(x, y) \geq 0$ for all $x, y \in X$, and if $d(x, y)=0$, then $x=y$;

(ii) $d(x, y)=d(y, x)$ for all $x, y \in X$;

(iii) $d(x, z) \leq d(x, y)+d(y, z)$ for all $x, y, z \in X$.

We call the pair $(X, d)$ a generalized metric space with

$$
d(x, y):=\left(\begin{array}{c}
d_{1}(x, y) \\
d_{2}(x, y) \\
\vdots \\
d_{m}(x, y)
\end{array}\right) .
$$

Notice that $d$ is a generalized metric space on $X$ if and only if $d_{i}, i=1, \ldots, m$, are metrics on $X$.

Definition 4.2 ([45]) A square matrix of real numbers is said to be convergent to zero if and only if its spectral radius $\rho(M)$ is strictly less than 1 . In other words, this means that all the eigenvalues of $M$ are in the open unit disc, i.e., $|\lambda|<1$ for every $\lambda \in \mathbb{C}$ with $\operatorname{det}(M-\lambda I)=0$, where $I$ denotes the unit matrix of $M_{m \times m}(\mathbb{R})$.

Example 4.3 The matrix $A \in M_{2 \times 2}(\mathbb{R})$ defined by

$$
A=\left(\begin{array}{ll}
a & b \\
c & d
\end{array}\right)
$$


converges to zero in the following cases:

(1) $b=c=0, a, d>0$, and $\max \{a, d\}<1$.

(2) $c=0, a, d>0, a+d<1$, and $-1<b<0$.

(3) $a+b=c+d=0, a>1, c>0$, and $|a-c|<1$.

Definition 4.4 Let $(X, d)$ be a generalized metric space. An operator $N: X \rightarrow X$ is said to be contractive if there exists a matrix $M$ convergent to zero such that

$$
d(N(x), N(y)) \leq M d(x, y) \quad \text { for all } x, y \in X .
$$

In the sequel we will make use of the following fixed point theorems in generalized Banach spaces.

Theorem 4.5 [36] Let $(X, d)$ be a complete generalized metric space and $N: X \rightarrow X$ be a contractive operator with Lipschitz matrix $M$. Then $N$ has a unique fixed point $x_{0}$, and for each $x \in X$, we have

$$
d\left(N^{k}(x), x_{0}\right) \leq M^{k}(M)^{-1} d(x, N(x)) \quad \text { for all } k \in \mathbb{N} .
$$

For $n=1$, we recover the classical Banach contraction fixed point result.

Theorem 4.6 ([36]) Let $X$ be a generalized Banach space, $D \subset E$ be a nonempty closed convex subset of $E$, and $N: D \rightarrow D$ be a continuous operator with relatively compact range. Then $N$ has at least a fixed point in $D$.

The following hypotheses will be used in the sequel.

$\left(H_{01}\right)$ There exist continuous functions $p_{i}, d_{i}, l_{i}: I \rightarrow \mathbb{R}_{+}, i=1,2$, such that $l_{i}<1$ and

$$
\begin{aligned}
& \left\|f_{i}\left(t, u_{1}, v_{1}, w_{1}\right)-f_{i}\left(t, u_{2}, v_{2}, w_{2}\right)\right\| \\
& \quad \leq p_{i}(t)\left\|u_{1}-u_{2}\right\|+d_{i}(t)\left\|v_{1}-v_{2}\right\|+l_{i}(t)\left\|w_{1}-w_{2}\right\|
\end{aligned}
$$

for a.e. $t \in I$ and each $u_{i}, v_{i}, w_{i} \in \mathbb{R}^{m}, i=1,2$.

$\left(H_{02}\right)$ There exist continuous functions $K_{i}, P_{i}, D_{i}, L_{i}: I \rightarrow \mathbb{R}_{+}, i=1,2$, such that

$$
\left\|f_{i}(t, u, v, w)\right\| \leq K_{i}(t)+P_{i}(t)\|u\|+D_{i}(t)\|v\|+L_{i}(t)\|w\|
$$

for a.e. $t \in I$ and each $u, v, w \in \mathbb{R}^{m}, i=1,2$.

Set

$$
\begin{aligned}
& p_{i}^{*}:=\sup _{t \in I} p_{i}(t), \quad d_{i}^{*}:=\sup _{t \in I} d_{i}(t), \quad l_{i}^{*}:=\sup _{t \in I} l_{i}(t), \quad K_{i}^{*}:=\sup _{t \in I} K_{i}(t), \\
& P_{i}^{*}:=\sup _{t \in I} P_{i}(t), \quad D_{i}^{*}:=\sup _{t \in I} D_{i}(t), \quad L_{i}^{*}:=\sup _{t \in I} L_{i}(t),
\end{aligned}
$$

and

$$
\ell_{i}:=\frac{T^{\alpha_{i}}}{\Gamma_{q}\left(1+\alpha_{i}\right)}, \quad i=1,2 .
$$


The space $C^{2}:=C \times C$ is a generalized Banach space with the norm

$$
\left\|\left(u_{1}, u_{2}\right)\right\|_{C^{2}}:=\left(\left\|u_{1}\right\|_{C},\left\|u_{2}\right\|_{C}\right)
$$

Definition 4.7 By a solution of problem (1)-(2) we mean a coupled continuous function $(u, v) \in C^{2}$ satisfying initial condition (2) and system (1) on $I$.

First, we prove an existence and uniqueness result for coupled system (1)-(2) by using Banach's fixed point theorem type in generalized Banach spaces.

Theorem 4.8 Assume that hypothesis $\left(H_{01}\right)$ holds. If the matrix

$$
M:=\left(\begin{array}{ll}
\frac{\ell_{1} p_{1}^{*}}{1-l_{1}^{*}} & \frac{\ell_{1} d_{1}^{*}}{1-l_{1}^{*}} \\
\frac{\ell_{2} p_{2}^{*}}{1-l_{2}^{*}} & \frac{\ell_{2} d_{2}^{*}}{1-l_{2}^{*}}
\end{array}\right)
$$

converges to 0 , then coupled system (1)-(2) has a unique solution.

Proof From Lemma 2.9, we can define the operators $N_{1}, N_{2}: C^{2} \rightarrow C$ by

$$
\left(N_{i}\left(u_{1}, u_{2}\right)\right)(t)=u_{0 i}+\left(I_{q}^{\alpha_{i}} g_{i}\right)(t), \quad i=1,2, t \in I
$$

where $g_{i}(\cdot) \in C(I)$, with

$$
\begin{aligned}
g_{i}(t) & =f_{i}\left(t, u_{1}(t), u_{2}(t), g_{i}(t)\right) \\
& =f_{i}\left(t, u_{01}+\left(I_{q}^{\alpha_{1}} g_{1}\right)(t), u_{02}+\left(I_{q}^{\alpha_{2}} g_{2}\right)(t), g_{i}(t)\right), \quad i=1,2 .
\end{aligned}
$$

Consider the operator $N: C^{2} \rightarrow C^{2}$ defined by

$$
\left(N\left(u_{1}, u_{2}\right)\right)(t)=\left(\left(N_{1}\left(u_{1}, u_{2}\right)\right)(t),\left(N_{2}\left(u_{1}, u_{2}\right)\right)(t)\right) .
$$

Clearly, the fixed points of the operator $N$ are solutions of coupled system (1)-(2). We show that $N$ satisfies all the conditions of Theorem 4.5.

For each $\left(u_{1}, u_{2}\right),\left(v_{1}, v_{2}\right) \in C^{2}$ and $t \in I$, we have

$$
\left\|\left(N_{i}\left(u_{1}, u_{2}\right)\right)(t)-\left(N_{i}\left(v_{1}, v_{2}\right)\right)(t)\right\| \leq \int_{0}^{t} \frac{(t-q s)^{(\alpha-i)}}{\Gamma_{q}\left(\alpha_{i}\right)}\left\|g_{i}(s)-h_{i}(s)\right\| d_{q} s,
$$

where $g_{i}(\cdot), h_{i}(\cdot) \in C(I), i=1,2$, with

$$
\begin{aligned}
g_{i}(t) & =f_{i}\left(t, u_{1}(t), u_{2}(t), g_{i}(t)\right) \\
& =f_{i}\left(t, u_{01}+\left(I_{q}^{\alpha_{1}} g_{1}\right)(t), u_{02}+\left(I_{q}^{\alpha_{2}} g_{2}\right)(t), g_{i}(t)\right)
\end{aligned}
$$

and

$$
\begin{aligned}
h_{i}(t) & =f_{i}\left(t, v_{1}(t), v_{2}(t), h_{i}(t)\right) \\
& =f_{i}\left(t, u_{01}+\left(I_{q}^{\alpha_{1}} h_{1}\right)(t), u_{02}+\left(I_{q}^{\alpha_{2}} h_{2}\right)(t), h_{i}(t)\right) .
\end{aligned}
$$


From hypothesis $\left(H_{01}\right)$, we have

$$
\left\|g_{i}(t)-h_{i}(t)\right\|=p_{i}(t)\left\|u_{1}(t)-v_{1}(t)\right\|+d_{i}(t)\left\|u_{2}-v_{2}\right\|+l_{i}(t)\left\|g_{i}-h_{i}\right\| .
$$

Then

$$
\left\|g_{i}(t)-h_{i}(t)\right\|=p_{i}(t)\left\|u_{1}(t)-v_{1}(t)\right\|+d_{i}(t)\left\|u_{2}(t)-v_{2}(t)\right\|+l_{i}(t)\left\|g_{i}(t)-h_{i}(t)\right\| .
$$

Thus

$$
\left\|g_{i}-h_{i}\right\|_{C}=p_{i}^{*}\left\|u_{1}-v_{1}\right\|_{C}+i_{1}^{*}\left\|u_{2}-v_{2}\right\|_{C}+l_{i}^{*}\left\|g_{i}-h_{i}\right\|_{C} .
$$

This implies that

$$
\left(1-l_{i}^{*}\right)\left\|g_{i}-h_{i}\right\|_{C}=p_{i}^{*}\left\|u_{1}-v_{1}\right\|_{C}+d_{i}^{*}\left\|u_{2}-v_{2}\right\|_{C} .
$$

Hence

$$
\left\|g_{i}-h_{i}\right\|_{C}=\frac{p_{i}^{*}}{1-l_{i}^{*}}\left\|u_{1}-v_{1}\right\|_{C}+\frac{d_{i}^{*}}{1-l_{i}^{*}}\left\|u_{2}-v_{2}\right\|_{C} .
$$

From (12), we get

$$
\begin{aligned}
\left\|\left(N_{i}\left(u_{1}, u_{2}\right)\right)-\left(N_{i}\left(v_{1}, v_{2}\right)\right)\right\|_{C} & \leq \int_{0}^{t} \frac{(t-q s)^{\left(\alpha_{i}-1\right)}}{\Gamma_{q}\left(\alpha_{i}-1\right)}\left\|g_{i}(s)-h_{i}(s)\right\| d_{q} s \\
& \leq \frac{\ell_{i} p_{i}^{*}}{1-l_{i}^{*}}\left\|u_{1}-v_{1}\right\|_{C}+\frac{\ell_{i} d_{i}^{*}}{1-l_{i}^{*}}\left\|u_{2}-v_{2}\right\|_{C} .
\end{aligned}
$$

Consequently,

$$
d\left(\left(N\left(u_{1}, u_{2}\right)\right),\left(N\left(v_{1}, v_{2}\right)\right)\right) \leq M d\left(\left(u_{1}, u_{2}\right),\left(v_{1}, v_{2}\right)\right),
$$

where

$$
d\left(\left(u_{1}, u_{2}\right),\left(v_{1}, v_{2}\right)\right)=\left(\begin{array}{l}
\left\|u_{1}-v_{1}\right\|_{C} \\
\left\|u_{2}-v_{2}\right\|_{C}
\end{array}\right) .
$$

Since the matrix $M$ converges to zero, then Theorem 4.5 implies that coupled system (1)(2) has a unique solution.

Now, we prove an existence result for coupled system (1)-(2) by using Schauder's fixed point theorem type in a generalized Banach space.

Theorem 4.9 Assume that hypothesis $\left(H_{02}\right)$ holds. Then coupled system (1)-(2) has at least one solution.

Proof Let $N: C^{2} \rightarrow C^{2}$ be the operator defined in (11). We show that $N$ satisfies all the conditions of Theorem 4.6. The proof will be given in several steps. 
Step 1. $N$ is continuous.

Let $\left\{\left(u_{1 n}, u_{2 n}\right)\right\}_{n}$ be a sequence such that $\left(u_{1 n}, u_{2 n}\right) \rightarrow\left(u_{1}, u_{2}\right) \in C^{2}$ as $n \rightarrow \infty$. For any $i=1,2$ and each $t \in I$, we have

$$
\left\|\left(N_{i}\left(u_{1 n}, u_{2 n}\right)\right)(t)-\left(N_{i}\left(u_{1}, u_{2}\right)\right)(t)\right\| \leq \int_{0}^{t} \frac{(t-q s)^{\left(\alpha_{i}-1\right)}}{\Gamma_{q}\left(\alpha_{i}-1\right)}\left\|g_{i n}(s)-g_{i}(s)\right\| d_{q} s,
$$

where $g_{i}(\cdot), g_{\text {in }}(\cdot) \in C(I), i=1,2$, with

$$
\begin{aligned}
g_{i}(t) & =f_{i}\left(t, u_{1}(t), u_{2}(t), g_{i}(t)\right) \\
& =f_{i}\left(t, u_{01}+\left(I_{q}^{\alpha_{1}} g_{1}\right)(t), u_{02}+\left(I_{q}^{\alpha_{2}} g_{2}\right)(t), g_{i}(t)\right)
\end{aligned}
$$

and

$$
\begin{aligned}
g_{i n}(t) & =f_{i}\left(t, u_{1 n}(t), u_{2 n}(t), g_{i n}(t)\right) \\
& =f_{i}\left(t, u_{01}+\left(I_{q}^{\alpha_{1}} g_{1 n}\right)(t), u_{02}+\left(I_{q}^{\alpha_{2}} g_{2 n}\right)(t), g_{i n}(t)\right) .
\end{aligned}
$$

From $\left(H_{02}\right)$, we have

$$
\left\|g_{i n}-g_{i}\right\|_{C} \leq \frac{P_{i}^{*}}{1-L_{i}^{*}}\left\|u_{1 n}-u_{1}\right\|_{C}+\frac{D_{i}^{*}}{1-L_{i}^{*}}\left\|u_{2 n}-u_{2}\right\|_{C}
$$

Thus,

$$
\begin{aligned}
\left\|\left(N_{i}\left(u_{1 n}, u_{2 n}\right)\right)(t)-\left(N_{i}\left(u_{1}, u_{2}\right)\right)(t)\right\| & \leq \frac{\ell_{i} P_{i}^{*}}{1-L_{i}^{*}}\left\|u_{1 n}-u_{1}\right\|_{C}+\frac{\ell_{i} D_{i}^{*}}{1-L_{i}^{*}}\left\|u_{2 n}-u_{2}\right\|_{C} \\
& \rightarrow 0 \quad \text { as } n \rightarrow \infty
\end{aligned}
$$

Hence, we get

$$
\left\|N_{i}\left(u_{1 n}, u_{2 n}\right)-N_{i}\left(u_{1}, u_{2}\right)\right\|_{C} \rightarrow 0 \quad \text { as } n \rightarrow \infty
$$

Consequently,

$$
\begin{aligned}
& \left\|N\left(u_{1 n}, u_{2 n}\right)-N\left(u_{1}, u_{2}\right)\right\|_{C^{2}} \\
& \quad:=\left(\left\|N_{1}\left(u_{1 n}, u_{2 n}\right)-N_{1}\left(u_{1}, u_{2}\right)\right\|_{C},\left\|N_{2}\left(u_{1 n}, u_{2 n}\right)-N_{2}\left(u_{1}, u_{2}\right)\right\|_{C}\right) \\
& \quad \rightarrow(0,0) \text { as } n \rightarrow \infty .
\end{aligned}
$$

Finally, $N$ is continuous.

Step 2. $N$ maps bounded sets into bounded sets in $C^{2}$.

Set

$$
h_{i}^{*}:=\sup _{t \in I} h_{i}(t), \quad k_{i}^{*}:=\sup _{t \in I} k_{i}(t), \quad l_{i}^{*}:=\sup _{t \in I} l_{i}(t) .
$$

Let $R>0$ and set

$$
B_{R}:=\left\{(\mu, v) \in C^{2}:\|\mu\|_{C} \leq R,\|v\|_{C} \leq R\right\} .
$$


For any $i=1,2$ and each $(u, v) \in B_{R}$ and $t \in I$, we have

$$
\left\|\left(N_{i}\left(u_{1}, u_{2}\right)\right)(t)\right\| \leq \int_{0}^{t} \frac{(t-q s)^{\left(\alpha_{i}-1\right)}}{\Gamma_{q}\left(\alpha_{i}-1\right)}\left\|g_{i}(s)\right\| d_{q} s,
$$

where $g_{i}(\cdot), \in C(I), i=1,2$, with

$$
\begin{aligned}
g_{i}(t) & =f_{i}\left(t, u_{1}(t), u_{2}(t), g_{i}(t)\right) \\
& =f_{i}\left(t, u_{01}+\left(I_{q}^{\alpha_{1}} g_{1}\right)(t), u_{02}+\left(I_{q}^{\alpha_{2}} g_{2}\right)(t), g_{i}(t)\right) .
\end{aligned}
$$

Since

$$
\left\|g_{i}\right\|_{C} \leq \frac{P_{i}^{*}}{1-L_{i}^{*}}\left\|u_{1}\right\|_{C}+\frac{D_{i}^{*}}{1-L_{i}^{*}}\left\|u_{2}\right\|_{C}
$$

we get

$$
\left\|N_{i}\left(u_{1}, u_{2}\right)\right\|_{C} \leq \frac{\ell_{i} P_{i}^{*}}{1-L_{i}^{*}}\left\|u_{1}\right\|_{C}+\frac{\ell_{i} D_{i}^{*}}{1-L_{i}^{*}}\left\|u_{2}\right\|_{C} .
$$

Thus,

$$
\left\|N_{i}\left(u_{1}, u_{2}\right)\right\|_{C} \leq \frac{R \ell_{i} P_{i}^{*}}{1-L_{i}^{*}}+\frac{R \ell_{i} D_{i}^{*}}{1-L_{i}^{*}}:=M_{i} .
$$

Hence,

$$
\|(N(u, v))\|_{C^{2}} \leq\left(M_{1}, M_{2}\right):=M
$$

Step 3. $N$ maps bounded sets into equicontinuous sets in $C^{2}$.

Let $B_{R}$ be the ball defined in Step 2 . For each $t_{1}, t_{2} \in I$ with $t_{1} \leq t_{2}$ and any $(u, v) \in B_{R}$ and $i=1,2$, we have

$$
\begin{aligned}
& \left\|\left(N_{i}\left(u_{1}, u_{2}\right)\right)\left(t_{1}\right)-\left(N_{i}\left(u_{1}, u_{2}\right)\right)\left(t_{2}\right)\right\| \\
& \quad \leq \int_{0}^{t_{1}} \frac{\left(t_{1}-q s\right)^{\left(\alpha_{i}-1\right)}}{\Gamma_{q}\left(\alpha_{i}-1\right)}\left\|g_{i}(s)\right\| d_{q} s-\int_{0}^{t_{2}} \frac{\left(t_{2}-q s\right)^{\left(\alpha_{i}-1\right)}}{\Gamma_{q}\left(\alpha_{i}-1\right)}\left\|g_{i}(s)\right\| d_{q} s,
\end{aligned}
$$

where $g_{i}(\cdot), \in C(I), i=1,2$, with

$$
\begin{aligned}
g_{i}(t) & =f_{i}\left(t, u_{1}(t), u_{2}(t), g_{i}(t)\right) \\
& =f_{i}\left(t, u_{01}+\left(I_{q}^{\alpha_{1}} g_{1}\right)(t), u_{02}+\left(I_{q}^{\alpha_{2}} g_{2}\right)(t), g_{i}(t)\right) .
\end{aligned}
$$


Thus,

$$
\begin{aligned}
& \left\|\left(N_{i}\left(u_{1}, u_{2}\right)\right)\left(t_{1}\right)-\left(N_{i}\left(u_{1}, u_{2}\right)\right)\left(t_{2}\right)\right\| \\
& \leq\left(\frac{R P_{i}^{*}}{1-L_{i}^{*}}+\frac{R D_{i}^{*}}{1-L_{i}^{*}}\right) \int_{0}^{t_{1}} \frac{\left|\left(t_{2}-q s\right)^{\left(\alpha_{i}-1\right)}-\left(t_{1}-q s\right)^{\left(\alpha_{i}-1\right)}\right|}{\Gamma_{q}\left(\alpha_{1}\right)} d_{q} s \\
& \quad+\left(\frac{R P_{i}^{*}}{1-L_{i}^{*}}+\frac{R D_{i}^{*}}{1-L_{i}^{*}}\right) \int_{t_{1}}^{t_{2}} \frac{\left|\left(t_{2}-q s\right)^{\left(\alpha_{i}-1\right)}\right|}{\Gamma_{q}\left(\alpha_{i}\right)} d_{q} s \\
& \rightarrow 0 \quad \text { as } t_{1} \rightarrow t_{2} .
\end{aligned}
$$

Hence,

$$
\begin{aligned}
& \left\|\left(N\left(u_{1}, u_{2}\right)\right)\left(t_{1}\right)-\left(N\left(u_{1}, u_{2}\right)\right)\left(t_{2}\right)\right\| \\
& \quad=\left(\left\|\left(N_{1}\left(u_{1}, u_{2}\right)\right)\left(t_{1}\right)-\left(N_{1}\left(u_{1}, u_{2}\right)\right)\left(t_{2}\right)\right\|,\left\|\left(N_{2}\left(u_{1}, u_{2}\right)\right)\left(t_{1}\right)-\left(N_{2}\left(u_{1}, u_{2}\right)\right)\left(t_{2}\right)\right\|\right) \\
& \quad \rightarrow(0,0) \quad \text { as } t_{1} \rightarrow t_{2} .
\end{aligned}
$$

As a consequence of steps 1 to 3 together with Theorem 4.6, we can conclude that $N$ has at least one fixed point in $B_{R}$ which is a solution of our coupled system (1)-(2).

\section{Examples}

Example 1 Consider the following coupled system of implicit fractional $\frac{1}{4}$-difference equation:

$$
\left\{\begin{array}{l}
\left({ }^{c} D_{1}^{\frac{1}{2}} u\right)(t)=f_{1}\left(t, u(t), v(t),\left({ }^{c} D_{1}^{\frac{1}{2}} u\right)(t)\right), \\
\left({ }^{c} D_{\frac{1}{4}}^{\frac{1}{2}} v\right)(t)=f_{2}\left(t, u(t), v(t),\left({ }^{c} D_{\frac{1}{4}}^{\frac{1}{2}} v\right)(t)\right), \quad t \in[0,1] \\
(u(0), v(0))=(1,2),
\end{array}\right.
$$

where

$$
\left\{\begin{array}{l}
f_{1}(t, x, y, z)=\frac{c t^{2}}{1+|x|+|y|+|z|}\left(e^{-7}+\frac{1}{e^{t+5}}\right)\left(t^{2}+x t^{2}+z\right), \\
f_{2}(t, x, y, z)=\frac{c t^{2}}{e^{t+5}(1+|x|+|y|+|z|)}\left(e^{t}+t y+z\right)
\end{array} \quad t \in(0,1]\right.
$$

and $c>0$. Hypothesis $\left(H_{1}\right)$ is satisfied with

$$
\begin{aligned}
& p_{1}(t)=d_{1}(t)=\left(e^{-7}+\frac{1}{e^{t+5}}\right) c t^{4}, \\
& r_{1}(t)=\left(e^{-7}+\frac{1}{e^{t+5}}\right) c t^{2}, \quad p_{2}(t)=\frac{c t^{2}}{e^{t+4}}, \quad d_{2}=\frac{c t^{3}}{e^{t+5}}, \quad r_{2}(t)=\frac{c t^{2}}{e^{t+5}} .
\end{aligned}
$$

Also, condition (6) is satisfied. Indeed,

$$
r_{1}^{*}+r_{2}^{*}-r_{1}^{*} r_{2}^{*}+\left(1-r_{2}^{*}\right) L_{1} d_{1}^{*}+\left(1-r_{1}^{*}\right) L_{2} d_{2}^{*}<1
$$

implies the inequality

$$
(2+3 L) e^{-10} c^{2}-3(1+L) e^{-5} c+1>0,
$$


with

$$
L:=\frac{2}{\Gamma_{\frac{1}{4}}\left(\frac{1}{2}\right)}
$$

which is satisfied for all $c \in \mathbb{R}_{+}$because

$$
\Delta=9(1+L)^{2} e^{-10}-4(2+3 L) e^{-10}=\left(1+6 L+9 L^{2}\right) e^{-10}>0,
$$

and $(2+3 L) e^{-10}>0$. For example, if we take $c=1$, we can see that

$$
r_{1}^{*}+r_{2}^{*}-r_{1}^{*} r_{2}^{*}+\left(1-r_{2}^{*}\right) L_{1} d_{1}^{*}+\left(1-r_{1}^{*}\right) L_{2} d_{2}^{*}=3 e^{-5}(1+L)-e^{-10}(2+3 L)<1 .
$$

Hence, Theorem 3.8 implies that system (13) has at least a solution defined on $[0,1]$.

On the other hand, hypothesis $\left(H_{2}\right)$ is satisfied with $\Phi(t)=t^{2}$. Indeed, for each $t \in(0,1]$, there exists a real number $0<\epsilon<1$ such that $\epsilon<t \leq 1$, and

$$
\begin{aligned}
\left(I_{q}^{\alpha} \Phi\right)(t) & \leq \frac{t^{2}}{\epsilon^{2}\left(1+q+q^{2}\right)} \\
& \leq \frac{1}{\epsilon^{2}} \Phi(t) \\
& =\lambda_{\Phi} \Phi(t) .
\end{aligned}
$$

Consequently, problem (13) is generalized Ulam-Hyers-Rassias stable.

Example 2 Consider now the following coupled system of implicit fractional $\frac{1}{4}$-difference equations:

$$
\left\{\begin{array}{l}
\left({ }^{c} D_{\frac{1}{4}}^{\frac{1}{2}} u\right)(t)=f_{1}\left(t, u(t), v(t),\left({ }^{c} D_{\frac{1}{4}}^{\frac{1}{2}} u\right)(t)\right), \\
\left({ }^{c} D_{\frac{1}{4}}^{\frac{1}{2}} v\right)(t)=f_{2}\left(t, u(t), v(t),\left({ }^{c} D_{\frac{1}{4}}^{\frac{1}{2}} v\right)(t)\right), \quad t \in[0,1] \\
(u(0), v(0))=(1,2)
\end{array}\right.
$$

where

$$
\left\{\begin{array}{l}
f_{1}(t, x, y, z)=\frac{c t^{2}}{1+|x|+|y|+|z|}\left(e^{-7}+\frac{1}{e^{t+5}}\right)\left(x t^{2}+z\right), \quad t \in(0,1], \\
f_{2}(t, x, y, z)=\frac{c t^{2}}{e^{t+5}(1+|x|+|y|+|z|)}(t y+z) ;
\end{array}\right.
$$

and $c>0$. Hypothesis $\left(H_{01}\right)$ is satisfied with

$$
\begin{array}{ll}
p_{1}(t)=\left(e^{-7}+\frac{1}{e^{t+5}}\right) c t^{4}, & d_{1}(t)=0, \\
l_{1}(t)=\left(e^{-7}+\frac{1}{e^{t+5}}\right) c t^{2}, & p_{2}(t)=0, \quad d_{2}=\frac{c t^{3}}{e^{t+5}}, \quad l_{2}(t)=\frac{c t^{2}}{e^{t+5}} .
\end{array}
$$

Also, with a good choice of the constant $c$, the matrix

$$
M:=\left(\begin{array}{cc}
\frac{\ell_{1} p_{1}^{*}}{1-l_{1}^{*}} & 0 \\
0 & \frac{\ell_{2} d_{2}^{*}}{1-l_{2}^{*}}
\end{array}\right)
$$


converges to 0 . Hence, Theorem 4.8 implies that system (14) has a unique solution defined on $[0,1]$.

\section{Conclusion}

We have provided sufficient conditions for the existence, uniqueness, and Ulam stability of the solutions of two classes of coupled implicit Caputo fractional q-difference systems with initial conditions. Suitable fixed point theorems have been used. As illustration, we have presented two examples.

\section{Funding}

YZ was supported by the Macau Science and Technology Development Fund (Grant No. 0074/2019/A2) from the Macau Special Administrative Region of the People's Republic of China and the National Natural Science Foundation of China (No. 11671339). BS was supported by Researchers Supporting Project RSP-2019/4, King Saud University, Riyadh, Saudi Arabia.

Availability of data and materials

Not applicable.

\section{Competing interests}

The authors declare that they have no competing interests.

\section{Authors' contributions}

Each of the authors, SA, MB, BS, and $\mathrm{YZ}$, contributed equally to each part of this work. All authors read and approved the final manuscript.

\section{Author details}

${ }^{1}$ Department of Mathematics, Tahar Moulay University of Saïda, Saïda, Algeria. ${ }^{2}$ Laboratory of Mathematics, Djillali Liabes University of Sidi Bel-Abbès, Sidi Bel-Abbès, Algeria. ${ }^{3}$ Department of Mathematics, College of Science, King Saud University, Riyadh, Saudi Arabia. ${ }^{4}$ Faculty of Information Technology, Macau University of Science and Technology, Macau, China. ${ }^{5}$ Faculty of Mathematics and Computational Science, Xiangtan University, Hunan, China.

\section{Publisher's Note}

Springer Nature remains neutral with regard to jurisdictional claims in published maps and institutional affiliations.

Received: 16 September 2019 Accepted: 27 November 2019 Published online: 19 December 2019

\section{References}

1. Abbas, S., Al Arifi, N., Benchohra, M., Graef, J.: Random coupled systems of implicit Caputo-Hadamard fractional differential equations with multi-point boundary conditions in generalized Banach spaces. Dyn. Syst. Appl. 28(2), 229-350 (2019)

2. Abbas, S., Al Arifi, N., Benchohra, M., Zhou, Y.: Random coupled Hilfer and Hadamard fractional differential systems in generalized Banach spaces. Mathematics 7, Article ID 285 (2019)

3. Abbas, S., Albarakati, W., Benchohra, M., N'Guérékata, G.M.: Existence and Ulam stabilities for Hadamard fractional integral equations in Fréchet spaces. J. Fract. Calc. Appl. 7(2), 1-12 (2016)

4. Abbas, S., Benchohra, M., Graef, J.R., Henderson, J.: Implicit Fractional Differential and Integral Equations: Existence and Stability. de Gruyter, Berlin (2018)

5. Abbas, S., Benchohra, M., N'Guérékata, G.M.: Topics in Fractional Differential Equations. Springer, New York (2012)

6. Abbas, S., Benchohra, M., N'Guérékata, G.M.: Advanced Fractional Differential and Integral Equations. Nova Science Publishers, New York (2015)

7. Abdeljawad, T., Alzabut, J.: On Riemann-Liouville fractional $q$-difference equations and their application to retarded logistic type model. Math. Methods Appl. Sci. 41(18), 8953-8962 (2018)

8. Abdeljawad, T., Alzabut, J., Baleanu, D.: A generalized q-fractional Gronwall inequality and its applications to nonlinear delay q-fractional difference systems. J. Inequal. Appl. 2016, Article ID 240 (2019)

9. Abdeljawad, T., Baleanu, D.: Caputo q-fractional initial value problems and a q-analogue Mittag-Leffler function. Commun. Nonlinear Sci. Numer. Simul. 16(12), 4682-4688 (2011)

10. Adams, C.R.: On the linear ordinary q-difference equation. Ann. Math. 30, 195-205 (1928)

11. Agarwal, R.: Certain fractional q-integrals and q-derivatives. Proc. Camb. Philos. Soc. 66, 365-370 (1969)

12. Ahmad, B.: Boundary value problem for nonlinear third order q-difference equations. Electron. J. Differ. Equ. 2011, Article ID 94 (2011)

13. Ahmad, B., Ntouyas, S.K., Purnaras, L.K.: Existence results for nonlocal boundary value problems of nonlinear fractional q-difference equations. Adv. Differ. Equ. 2012, Article ID 140 (2012)

14. Al-Salam, W.A.: q-Analogues of Cauchy's formula. Proc. Am. Math. Soc. 17, 1952-1953 (1824)

15. Al-Salam, W.A.: Some fractional q-integrals and q-derivatives. Proc. Edinb. Math. Soc. 15, 135-140 (1969)

16. Al-Salam, W.A., Verma, A.: A fractional Leibniz q-formula. Pac. J. Math. 60, 19 (1975) 
17. Ali, A., Shah, K., Jarad, F., Gupta, V., Abdeljawad, T.: Existence and stability analysis to a coupled system of implicit type impulsive boundary value problems of fractional-order differential equations. Adv. Differ. Equ. 2019, Article ID 101 (2019)

18. Ali, S., Abdeljawad, T., Shah, K., Jarad, F., Arif, M.: Computation of iterative solutions along with stability analysis to a coupled system of fractional order differential equations. Adv. Differ. Equ. 2019, Article ID 215 (2019)

19. Ali, Z., Kumam, P., Shah, K., Zada, A.: Investigation of Ulam stability results of a coupled system of nonlinear implicit fractional differential equations. Mathematics 7(4), Article ID 341 (2019)

20. Ameen, R., Jarad, F., Abdeljawad, T.: Ulam stability for delay fractional differential equations with a generalized Caputo derivative. Filomat 32(15), 5265-5274 (2018)

21. Annaby, M.H., Mansour, Z.S.: q-Fractional Calculus and Equations. Lecture Notes in Mathematics, vol. 2056. Springer, Heidelberg (2012)

22. Benchohra, M., Bouriah, S., Henderson, J.: Existence and stability results for nonlinear implicit neutral fractional differential equations with finite delay and impulses. Commun. Appl. Nonlinear Anal. 22(1), 46-67 (2015)

23. Benchohra, M., Bouriah, S., Nieto, J.J.: Existence of periodic solutions for nonlinear implicit Hadamard's fractional differential equations. Rev. R. Acad. Cienc. Exactas Fís. Nat., Ser. A Mat. 112(1), 25-35 (2019)

24. Carmichael, R.D.: The general theory of linear q-difference equations. Am. J. Math. 34, 147-168 (1912)

25. El-Shahed, M., Hassan, H.A.: Positive solutions of q-difference equation. Proc. Am. Math. Soc. 138, 1733-1738 (2010)

26. Ernst, T.: A Comprehensive Treatment of q-Calculus. Birkhäuser, Basel (2012)

27. Etemad, S., Ntouyas, S.K., Ahmad, B.: Existence theory for a fractional q-integro-difference equation with q-integral boundary conditions of different orders. Mathematics 7, Article ID 659 (2019)

28. Jarad, F., Abdeljawad, T., Baleanu, D.: Stability of q-fractional non-autonomous systems. Nonlinear Anal., Real World Appl. 14(1), 780-784 (2013)

29. Jung, S.-M.: Hyers-Ulam-Rassias Stability of Functional Equations in Nonlinear Analysis. Springer, New York (2011)

30. Kac, V., Cheung, P.: Quantum Calculus. Springer, New York (2002)

31. Khan, A., Khan, H., Gómez-Aguilar, J.F., Abdeljawad, T.: Existence and Hyers-Ulam stability for a nonlinear singular fractional differential equation with Mittag-Leffler kernel. Chaos Solitons Fractals 127, 422-427 (2019)

32. Khan, H., Abdeljawad, T., Aslam, M., Khan, R.A., Khan, A.: Existence of positive solution and Hyers-Ulam stability for a nonlinear singular-delay-fractional differential equation. Adv. Differ. Equ. 2019, Article ID 104 (2019)

33. Kilbas, A.A., Srivastava, H.M., Trujillo, J.J.: Theory and Applications of Fractional Differential Equations. North-Holland Mathematics Studies, vol. 204. Elsevier, Amsterdam (2006)

34. Nieto, J.J., Ouahab, A., Venktesh, V.: Implicit fractional differential equations via the Liouville-Caputo derivative. Mathematics 3(2), 398-411 (2015)

35. Noeiaghdam, Z., Allahviranloo, T., Nieto, J.J.: q-Fractional differential equations with uncertainty. Soft Comput. 23(19), 9507-9524 (2019)

36. Petre, I.R., Petruşel, A.: Krasnoselskii's theorem in generalized Banach spaces and applications. Electron. J. Qual. Theory Differ. Equ. 2012, Article ID 85 (2012)

37. Rajkovic, P.M., Marinkovic, S.D., Stankovic, M.S.: Fractional integrals and derivatives in q-calculus. Appl. Anal. Discrete Math. 1, 311-323 (2007)

38. Rajkovic, P.M., Marinkovic, S.D., Stankovic, M.S.: On q-analogues of Caputo derivative and Mittag-Leffler function. Fract. Calc. Appl. Anal. 10, 359-373 (2007)

39. Rassias, Th.M.: On the stability of linear mappings in Banach spaces. Proc. Am. Math. Soc. 72, 297-300 (1978)

40. Rus, I.A.: Ulam stability of ordinary differential equations. Stud. Univ. Babeş-Bolyai, Math. LIV(4), 125-133 (2009)

41. Rus, I.A.: Remarks on Ulam stability of the operatorial equations. Fixed Point Theory 10, 305-320 (2009)

42. Samko, S.G., Kilbas, A.A., Marichev, O.I.: Fractional Integrals and Derivatives. Theory and Applications. Gordon \& Breach, Amsterdam (1987). English translation from the Russian

43. Shah, K.S., Khan, R.A., Baleanu, D.: Study of implicit type coupled system of non-integer order differential equations with anti-periodic boundary conditions. Math. Methods Appl. Sci. 42(6), 2033-2042 (2019)

44. Tarasov, V.E.: Fractional Dynamics: Application of Fractional Calculus to Dynamics of Particles, Fields and Media. Springer, Heidelberg; Higher Education Press, Beijing (2010)

45. Varga, R.S.: Matrix Iterative Analysis, 2nd revised and expanded edn. Springer Series in Computational Mathematics, vol. 27. Springer, Berlin (2000)

46. Wang, J., Li, X.: A uniformed method to Ulam-Hyers stability for some linear fractional equations. Mediterr. J. Math. 13, 625-635 (2016)

47. Zhou, Y.: Basic Theory of Fractional Differential Equations. World Scientific, Singapore (2014)

\section{Submit your manuscript to a SpringerOpen ${ }^{\circ}$ journal and benefit from:}

- Convenient online submission

- Rigorous peer review

- Open access: articles freely available online

- High visibility within the field

- Retaining the copyright to your article

Submit your next manuscript at $>$ springeropen.com 